\section{Compact Antenna based on a Composite Right/Left Handed Transmission Line}

Mohammad Alibakhshi-Kenari ${ }^{1}$, Mohammad Naser-Moghadasi ${ }^{2}$, Bal S. Virdee ${ }^{3}$, Aurora Andujar ${ }^{4}$, and Jaume Anguera ${ }^{5}$

${ }^{1}$ School of Electrical and Communication Engineering, Shahid Bahonar University, Kerman, Iran

${ }^{2}$ Faculty of Engineering, Science and Research Branch, Islamic Azad University, Tehran, Iran

${ }^{3}$ Faculty of Life Sciences and Computing, London Metropolitan University, Center for Communications Technology, London N7 8DB, United Kingdom

${ }^{4}$ School of Telecommunication Engineering, Universitat Ramon Llull, Barcelona, Spain

\begin{abstract}
This Letter presents a novel antenna that is based on composite right-left handed (CRLH) transmission-line unitcells implemented using slots and spiral inductors that are etched directly on the dielectric substrate by standard manufacturing techniques. The antenna is designed to operate across 5.8-7.3 GHz, which corresponds to a fractional bandwidth of $23 \%$. Measured results confirm the antenna exhibits a relatively wide bandwidth, high gain and high radiation efficiency characteristics. The measured radiation gain, bandwidth and efficiency of the antenna at $6.6 \mathrm{GHz}$ are $4.8 \mathrm{dBi}, 23 \%$ and $78 \%$, respectively. The fabricated antenna is highly compact and its physical size in terms of the free-space wavelength is $0.39 \lambda_{0} \times 0.13 \lambda_{0} \times 0.015 \lambda_{0}$.
\end{abstract}

Index Terms - Broadband antenna, composite right-left handed transmission-lines.

\section{INTRODUCTION}

Transmission-lines are essential components in modern wireless systems as they are used, for example, to connect antennas to transmitters and receivers, for impedance matching in mixers and amplifiers, or as resonant elements in oscillators and filters [1]-[5]. More recently, the composite right/left-handed transmission-line (CRLH-TL) or metamaterials (MTMs) have been developed as a novel paradigm in electromagnetics engineering and have been shown to possess a rich potential for novel microwave devices with unprecedented properties [6]-[9].

In this Letter, a novel compact planar antenna is proposed that is constituted from CRLH-TLs. Size reduction and bandwidth extension have realized using the CRLH-TL unit-cells that are composed of U-shaped slot and spiral inductor that is grounded using via-holes. The CRLH-TL unit-cell behave as series left-handed capacitance $\left(C_{L}\right)$ and shunt inductance $\left(L_{L}\right)$, respectively [10]-[12]. It is shown the antenna's radiation characteristics can be easily modified by using an appropriate number of CRLH-TL unit-cells.

\section{THE METAMATERIAL ANTENNA}

The configuration of the proposed antenna, shown in Fig. 1, consists of rectangular radiating patch that includes six CRLH unit-cells, where each unit-cell is constructed from a U-shaped slot and spiral inductor that is connected to the ground-plane through a metallic via-hole. The U-shaped slot and spiral act like series left-handed (LH) capacitance $\left(C_{L}\right)$ and shunt $(\mathrm{LH})$ inductance $\left(L_{L}\right)$, respectively. The proposed metamaterial antenna was fabricated on a Rogers RO4003 substrate with dielectric constant of 3.38, thickness of $0.8 \mathrm{~mm}$ and $\tan \delta=0.0022$.

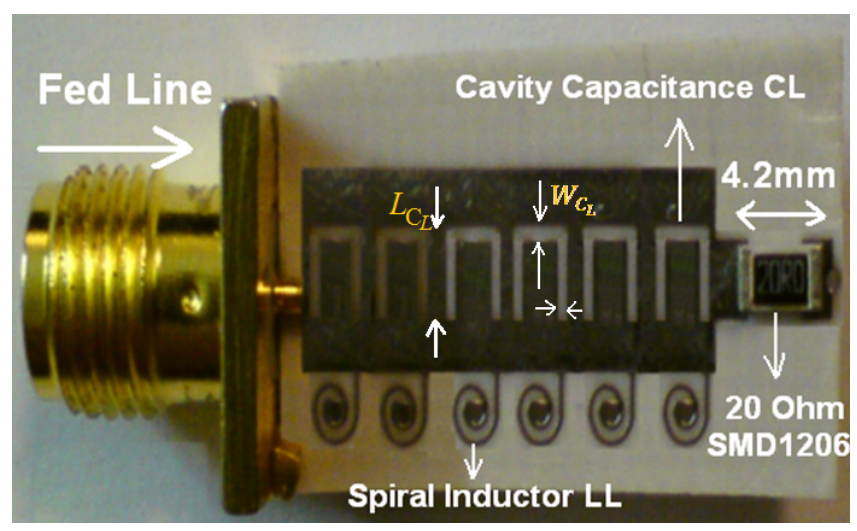

Fig. 1. Fabricated prototype of the proposed metamaterial antenna.

The criteria used to determine the number of CRLH-TL unit-cells depends on a tradeoff between the antenna dimensions, impedance bandwidth and radiation characteristics. The overall goal here was to design and implement an antenna that had a maximum length of $20 \mathrm{~mm}$ and exhibited a wide bandwidth with good unidirectional radiation patterns. The number of unit-cells was determined through optimization using High Frequency Simulator Structure (HFSS). Fig. 2 shows the reflection-coefficient of the antenna with increasing number of unit-cells from 1-6. Six unit-cells provide the widest impedance bandwidth of $1.75 \mathrm{GHz}$ for a reflection-coefficient of $-10 \mathrm{~dB}$. Therefore six unit-cells were used here in the antenna design.

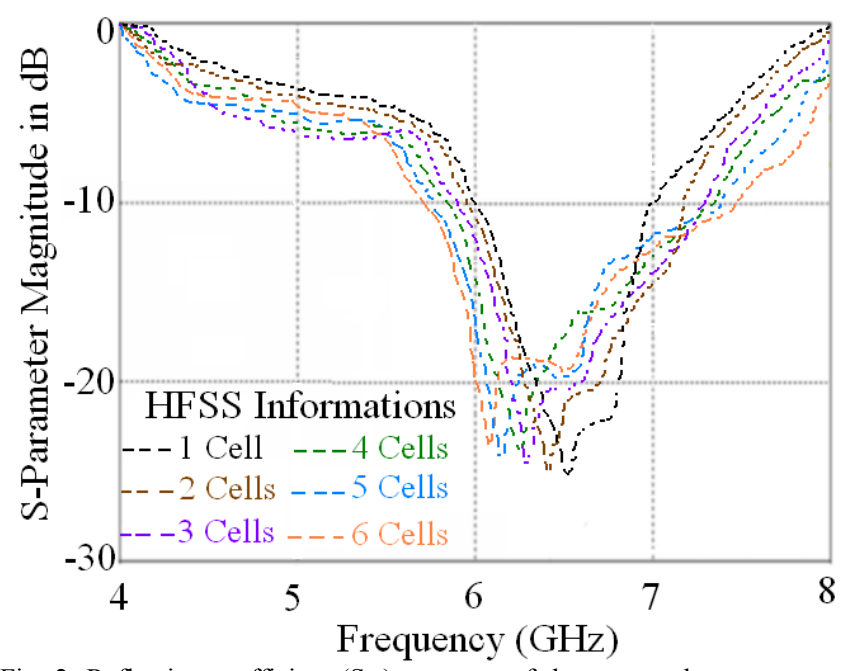

Fig. 2. Reflection-coefficient $\left(\mathrm{S}_{11}\right)$ response of the proposed antenna as a function of number of cells.

The proposed antenna, shown in Fig. 1, consists of a rectangular radiating patch which is embedded with six U- 
shaped slots and includes six spiral inductors terminated to the ground-plane using via-holes. The antenna is terminated on the right hand side to a matched load of $20 \Omega$ using SMD1206. The load is terminated to the ground-plane through a via-hole.

The antenna structure generates parasitic right-handed (RH) effect from the series inductance $\left(L_{R}\right)$ and the shunt capacitance $\left(C_{R}\right)$ resulting from current flowing over the antenna metallization, and the voltage gradient developed between the metallization and the ground-plane. The equivalent circuit model of the CRLH-TL unit-cell is shown in Fig. 3. In addition to the four reactive components $\left(C_{L}\right.$, $L_{L}, L_{R}$ and $C_{R}$ ) are included right-handed lossy components $R_{R}$ and $G_{R}$, and left-handed lossy components $G_{L}$ and $R_{L}$, which account for the dielectric loss associated with $C_{L}$ and the ohmic loss associated with $L_{L}$. The magnitude of the CRLH-TL unit-cell parameters were determined from simulation, and these are: $\mathrm{C}_{\mathrm{L}}=3.2 \mathrm{pF}, \mathrm{L}_{\mathrm{L}}=4.5 n \mathrm{H}, \mathrm{C}_{\mathrm{R}}=1.5$ $p F, \mathrm{~L}_{\mathrm{R}}=3.44 n H, \mathrm{G}_{\mathrm{L}}=5.6 \mathrm{~S}, \mathrm{G}_{\mathrm{R}}=3.2 \mathrm{~S}, \mathrm{R}_{\mathrm{L}}=6 \Omega$, and $\mathrm{R}_{\mathrm{R}}=$ $4.2 \Omega$.

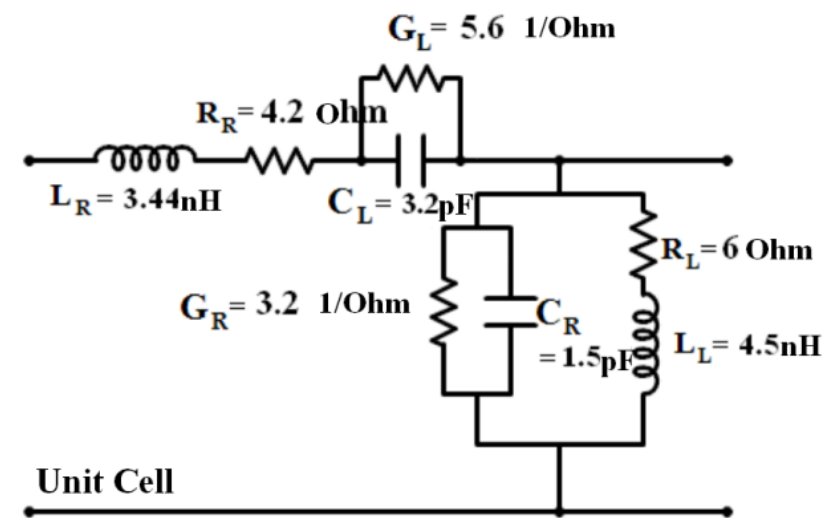

Fig. 3. Equivalent circuit model of the antenna unit-cell.

The results of the parametric study, i.e. slot length and width, are shown in Figs. 4 and 5, respectively. The results show a shorter slot length enhances the impedance bandwidth of the antenna. In fact a reduction of the slot length from $2.9 \mathrm{~mm}$ to $2.5 \mathrm{~mm}$ increases the bandwidth from $1 \mathrm{GHz}$ to $1.75 \mathrm{GHz}$ for reflection-coefficient of -10 $\mathrm{dB}$. The slot width has the same effect on the impedance bandwidth, i.e. a reduction of slot width from $0.7 \mathrm{~mm}$ to 0.5 $\mathrm{mm}$ results in an increase of the impedance bandwidth by $68 \%$. The optimized length and width of the U-shaped slot were determined from these results to be $2.5 \mathrm{~mm}$ and 0.5 $\mathrm{mm}$, respectively. The proposed antenna is constructed using six CRLH-TL unit-cells, each of which occupies a space of $2.7 \times 6.8 \mathrm{~mm}^{2}$ or $0.052 \lambda_{0} \times 0.13 \lambda_{0}$ in terms of the free-space wavelength at $f=5.8 \mathrm{GHz}$. The total length, width and height of the antenna are $0.39 \lambda_{0}(20.4 \mathrm{~mm}), 0.13 \lambda_{0}(6.8 \mathrm{~mm})$ and $0.015 \lambda_{0}(0.8 \mathrm{~mm})$, respectively.

The simulated and measured reflection-coefficients of the antenna are shown in Fig. 6. The simulated impedance bandwidths are 29\%, 26.8\% and 26.6\% using Advanced Design System (ADS), High Frequency Structure Simulator (HFSS) and CST MWS, respectively. The measured impedance bandwidth of the antenna is $1.5 \mathrm{GHz}$ from 5.8 $\mathrm{GHz}$ to $7.3 \mathrm{GHz}$ for a reflection-coefficient $<-10 \mathrm{~dB}$, which corresponds to $23.7 \%$. There is $13.7 \%$ differential between the averaged simulation and measurement results.

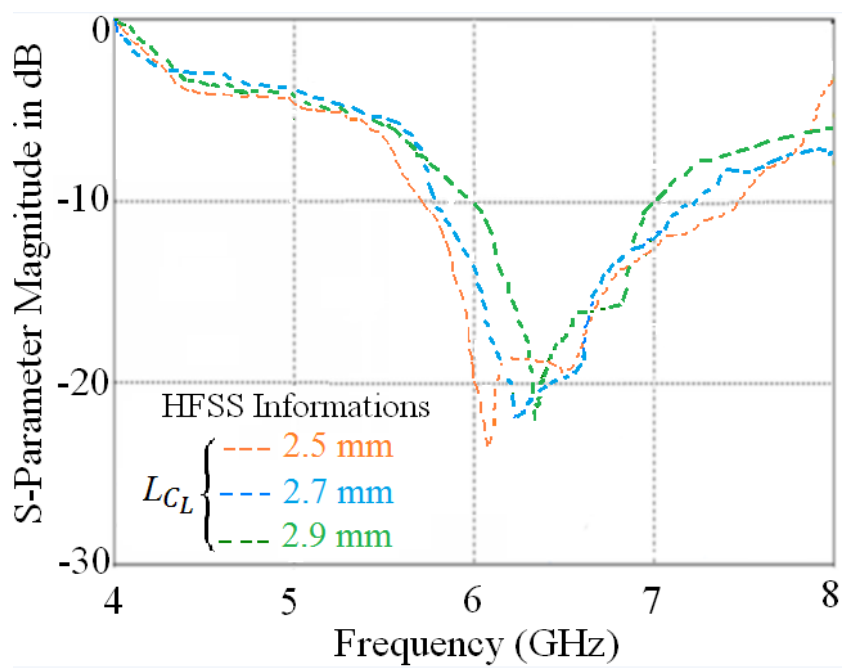

Fig. 4. Reflection-coefficient $\left(\mathrm{S}_{11}\right)$ response of the antenna as a function of the slot length. The slot width was kept fixed at $0.5 \mathrm{~mm}$.

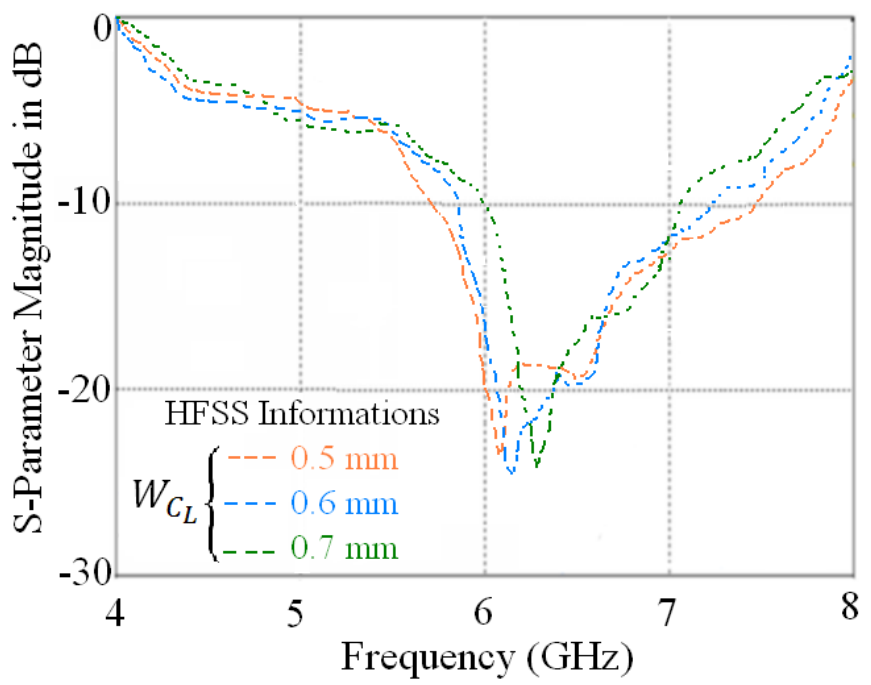

Fig. 5. Reflection-coefficient $\left(\mathrm{S}_{11}\right)$ response of the antenna as a function of the slot width. The slot length was fixed at $2.5 \mathrm{~mm}$.

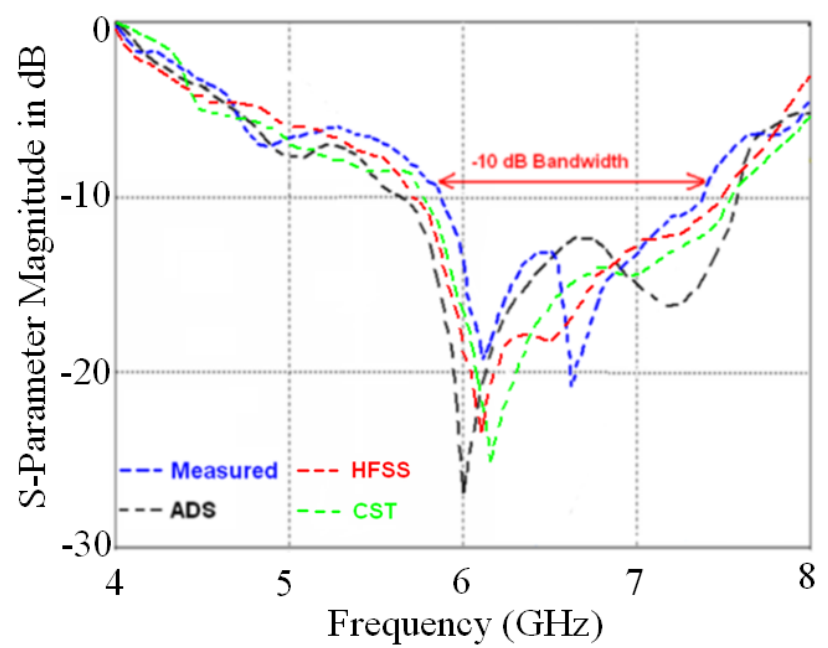

Fig. 6. Measured and simulated reflection-coefficients antenna. 
Besides the requirement of compact size and wide bandwidth, the antenna needed to possess good radiation characteristics such as gain and efficiency. It's well known the extension of the effective aperture of the antenna improves it gain and efficiency performance. Conventionally this can be achieved by increasing the effective cross-sectional area of antenna. The proposed antenna's effective aperture was increased by simply increasing the number of CRLH-TL unit-cells, which is confirmed in Fig. 7, without increasing its physical size. Antenna with four unit-cells provides a gain and efficiency of $4.94 \mathrm{dBi}$ and $74 \%$, respectively, at $7 \mathrm{GHz}$. Increasing the unit-cells from four to six results in gain and efficiency improvement to $6.1 \mathrm{dBi}$ and $85 \%$, respectively.

The optimized dimensions of the antenna parameters and equivalent electrical circuit are given in Table I.

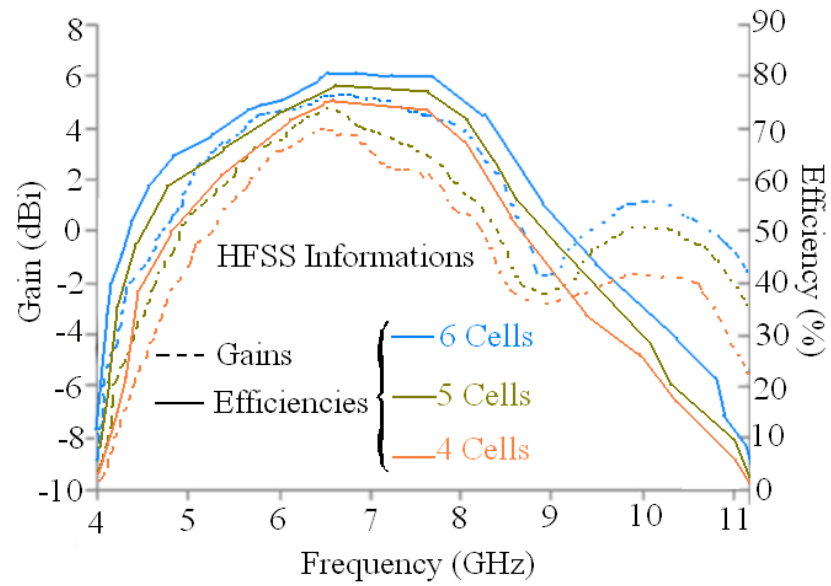

Fig. 7. Gain and efficiency performance as a function of number of CRLHTL unit-cells.

Table I - Dimensions of Antenna and Parameter values

\begin{tabular}{|c|c|}
\hline Number of Unit Cells & 6 \\
\hline Length of Cavities $\left(L_{C_{L}}\right)$ & $2.50 \mathrm{~mm}$ \\
\hline Width of Cavities $\left(W_{C_{L}}\right)$ & $0.50 \mathrm{~mm}$ \\
\hline Distances between Slits & $0.60 \mathrm{~mm}$ \\
\hline Width of Spirals & $0.25 \mathrm{~mm}$ \\
\hline Spacing of Spirals & $0.25 \mathrm{~mm}$ \\
\hline Turns of Spirals & 2 \\
\hline Height of Via Hole & $0.80 \mathrm{~mm}$ \\
\hline Length of SMD1206 & $4.20 \mathrm{~mm}$ \\
\hline Amount of SMD1206 & $20 \Omega$ \\
\hline$C_{L}$ & $3.2 \mathrm{pF}$ \\
\hline$L_{L}$ & $4.5 \mathrm{nH}$ \\
\hline$C_{R}$ & $1.5 \mathrm{pF}$ \\
\hline$L_{R}$ & $3.4 \mathrm{nH}$ \\
\hline$G_{L}$ & $5.6 \mathrm{~S}$ \\
\hline$G_{R}$ & $3.2 \mathrm{~S}$ \\
\hline$R_{L}$ & $6.0 \Omega$ \\
\hline$R_{R}$ & $4.2 \Omega$ \\
\hline & \\
\hline
\end{tabular}

Three simulation tools, i.e. ADS, HFSS and CST MWS, were used to compare the performance of the antenna. The antenna's performance was measured to validate the design. The simulated averaged gain and averaged efficiency of the antenna using HFSS, CST MWS and ADS are $4.5 \mathrm{dBi}$ and $76 \%$, respectively, at $5.8 \mathrm{GHz} ; 4.9 \mathrm{dBi}$ and $80 \%$, respectively, at $6.6 \mathrm{GHz}$; and $4.65 \mathrm{dBi}$ and $78 \%$, respectively, at $7.3 \mathrm{GHz}$. The measured gain and efficiency response are plotted in Fig. 8. The measured gain and efficiency are $4.3 \mathrm{dBi}$ and $74 \%$, respectively, at $5.8 \mathrm{GHz}$; $4.8 \mathrm{dBi}$ and $78 \%$, respectively, at $6.6 \mathrm{GHz}$; and $4.6 \mathrm{dBi}$ and $76 \%$, respectively, at $7.3 \mathrm{GHz}$.

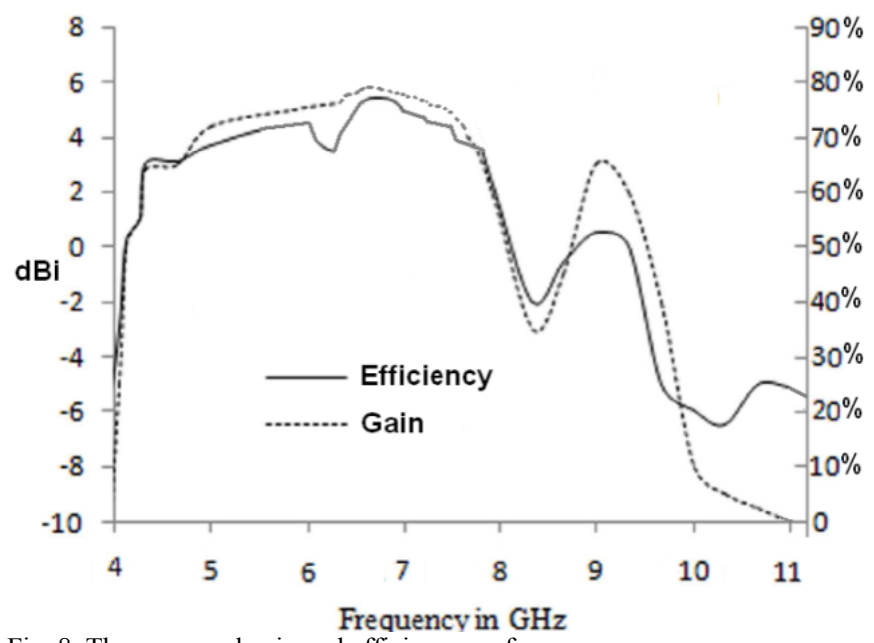

Fig. 8. The measured gain and efficiency performance.

The measured E-plane and $\mathrm{H}$-plane radiation patterns at spot frequencies of $5.8 \mathrm{GHz}, 6.6 \mathrm{GHz}$ and $7.3 \mathrm{GHz}$ are plotted in Fig. 9. The antenna radiates unidirectionally with $3 \mathrm{~dB}$ angular beamwidth of 90 degrees.

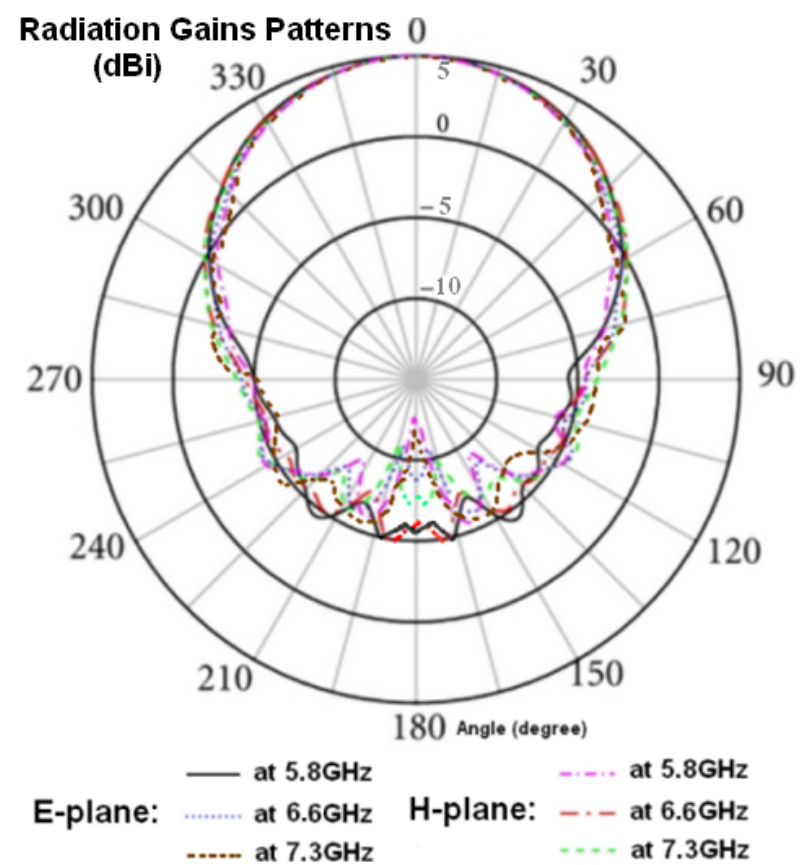

Fig. 9. E-plane and H-plane radiation patterns at 5.8, 6.6 and 7.3 GHz. 
The surface current distribution over the proposed antenna at various frequencies is shown in Fig. 10. The Ushaped slots affect the current flow over the antenna to generate the radiation patterns shown in Fig. 9 that are stable across its operating frequency range of $5.8 \mathrm{GHz}$ to 7.3 GHz.

Table II summarizes the antenna performance in terms of dimensions, impedance bandwidth, gain and efficiency. The proposed antenna has advantages of low profile, relatively wide impedance bandwidth, high gain, and high efficiency across $5.8 \mathrm{GHz}$ to $7.3 \mathrm{GHz}$. The antenna is simple to design and cost effective to manufacture.
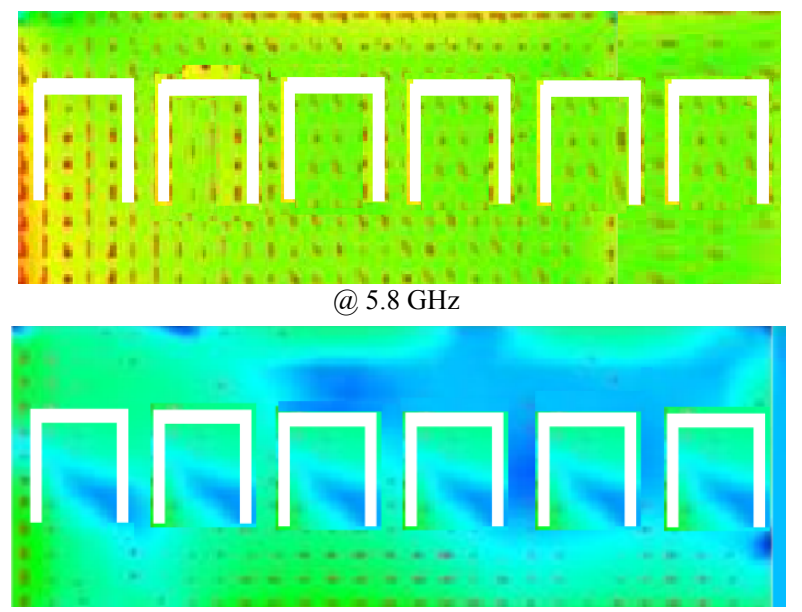

(a) $6.6 \mathrm{GHz}$

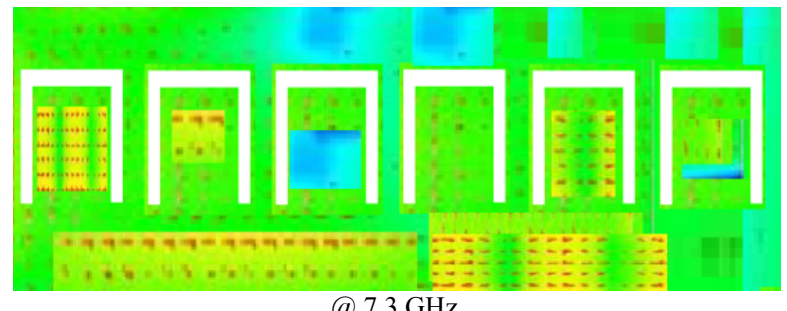

(a) $7.3 \mathrm{GHz}$

Fig. 10. Surface current density distribution over the antenna.

Table II. Summary of Antenna Performance

\begin{tabular}{|c|c|c|c|}
\hline Dimensions & $\begin{array}{c}\text { Impedance } \\
\text { bandwidth }\end{array}$ & $\begin{array}{c}\text { Gain (dBi) } \\
\text { @ freq. } \\
\text { (GHz) }\end{array}$ & $\begin{array}{c}\text { Efficiency @ } \\
\text { freq. (GHz) }\end{array}$ \\
\hline $\begin{array}{c}20.4 \times 6.8 \times 0.8 \mathrm{~mm}^{3} \\
\text { or }\end{array}$ & $23 \%$ & $4.3 @ 5.8$ & $74 \% @ 5.8$ \\
$0.39 \lambda_{0} \times 0.13 \lambda_{0} \times 0.015 \lambda_{0}$ & $(5.8-7.3 \mathrm{GHz})$ & $4.8 @ 6.6$ & $78 \% @ 6.6$ \\
$@ 5.8 \mathrm{GHz}$ & $4.6 @ 7.3$ & $76 \% @ 7.3$ \\
\hline
\end{tabular}

\section{CONCLUSION}

A compact and low profile antenna design is proposed that is based on composite right-left handed transmission-line unit-cells consisting of a U-shaped slot and a spiral inductor that is short-circuited to ground using via-holes. The rectangular antenna which is embedded with the unit-cells and the number of unit-cells is shown to determine the antenna's impedance bandwidth. The antenna's performance was validated through measurements. Over the operating frequency range of $5.8 \mathrm{GHz}$ to $7.3 \mathrm{GHz}$ it provides an average gain of $4.57 \mathrm{dBi}$ and an average efficiency of $76 \%$. Its unidirectional radiation pattern is stable over its operating frequency range.

\section{ACKNOWLEDGEMENTS}

The authors would like to express their sincere thanks to the Iran Telecommunication Research Center (ITRC) with grant number of $6987 / 500 / \mathrm{T}$, the microwave and millimeter wave laboratory of the Amirkabir University of Technology (Tehran Polytechnic) and the antenna laboratory of the K. N. Toosi University of Technology for supporting this project and providing the measured results.

\section{REFERENCES}

[1] R.E. Collin, Field Theory of Guided Waves, second Ed., Wiley- Inter science, 1991, chap. 12.

[2] C.A. Balanis, Antenna Theory and Design, John Wiley \& Sons, 1997.

[3] A. Rennings, S. Otto, J. Mosig, C. Caloz and I. Wolff, "Extended Composite Right/Left-Handed (E-CRLH) Metamaterial and its Application as a Quadband Quarter Wavelength Transmission Line," Asia-Pacific Microwave Conference, Yokohama, 12-15 Dec. 2006, pp. $1405-1408$.

[4] N. Engheta and R. W. Ziolkowski, "Electromagnetic Metamaterials: Physics and Engineering Explorations," Wiley and IEEE Press, Hoboken, 2006.

[5] S.G. Mao, S.L. Chen, C.W. Huang, "Effective Electromagnetic Parameters of Novel Distributed Left-Handed Microstrip Lines," IEEETrans. Microw. Theory Tech., Vol. 53, No. 4, 2005, pp. 15151521.

[6] A. Lai, C. Caloz, and T. Itoh, "Composite Right/Left Handed Transmission Line Metamaterials," IEEE Microwave Mag., Vol. 5, No. 3, Sept. 2004, pp. 34-50.

[7] C. Caloz and T. Itoh, Electromagnetic Metamaterials, Transmission Line Theory and Microwave Applications, Wiley and IEEE Press, 2005.

[8] C.J. Lee, K.M.K.H. Leong, T. Itoh, "Composite Right/Left-Handed Transmission Line Based Compact Resonant Antennas for RF Module Integration," IEEE Trans Antennas and Propagation, Vol. 54, No. 8, pp. 2283-2291.

[9] C. Caloz, T. Itoh, and A. Rennings, "CRLH Traveling-Wave and Resonant Metamaterial Antennas," Antennas Propagat. Magazine, Vol. 50, No. 5, 2008, pp. 25-39.

[10] M. Alibakhshi-Kenari, "Introducing the New Wide Band Small Plate Antennas with Engraved Voids to Form New Geometries Based on CRLH MTM-TLs for Wireless Applications," Int. Journal of Microwave and Wireless Technologies, March 2014, pp. 1-9, DOI:http://dx.doi.org/10.1017/S1759078714000099.

[11] M. Alibakhshi-Kenari, "Printed Planar Patch Antennas Based on Metamaterial" Int. Journal of Electronics Letters, Jan 2014, pp. 37-42, http://dx.doi.org/10.1080/21681724.2013.874042.

[12] M. Alibakhshi-Kenari, M. Movahhedi and H. Naderian, "A New Miniature Ultra Wide Band Planar Microstrip Antenna Based on the Metamaterial Transmission Line," 2012 IEEE Asia-Pacific Conference on Applied Electromagnetics, Dec. 11-13, 2012, Melaka, Malaysia. 